\title{
Effect of Women's Decision-Making Autonomy on Infant's Birth Weight in Rural Bangladesh
}

\author{
Arpana Sharma ${ }^{1}$ and Manzur Kader ${ }^{2}$ \\ ${ }^{1}$ Department of Community Medicine, Manipal College of Medical Sciences (MCOMS), 155 Pokhara, Nepal \\ ${ }^{2}$ Department of Women's and Children's Health, International Maternal and Child Health (IMCH), Uppsala University, \\ 75185 Uppsala, Sweden
}

Correspondence should be addressed to Arpana Sharma; arpanasharma20@gmail.com

Received 14 September 2013; Accepted 11 November 2013

Academic Editors: M. Adhikari, S. K. Patole, and S. A. Sarker

Copyright (c) 2013 A. Sharma and M. Kader. This is an open access article distributed under the Creative Commons Attribution License, which permits unrestricted use, distribution, and reproduction in any medium, provided the original work is properly cited.

\begin{abstract}
Background. Low birth weight (LBW), an outcome of maternal undernutrition, is a major public health concern in Bangladesh where the problem is most prominent. Women's decision-making autonomy is likely an important factor influencing maternal and child health outcomes. The aim of the study was to assess the effect of women's decision-making autonomy on infant's birth weight (BW). Methods. The study included data of 2175 enrolled women (14-45 years of age) from the Maternal and Infant Nutritional Intervention in Matlab (MINIMat-study) in Bangladesh. Pearson's chi-square test, analysis of covariance (ANCOVA), and logistic regression analysis were applied at the collected data. Results. Women with lowest decision-making autonomy were significantly more likely to have a low birth weight (LBW) child, after controlling for maternal age, education (woman's and her husband's), socioeconomic status (SES) (odds ratio $(\mathrm{OR})=1.4$; 95\% confidence interval $(\mathrm{CI}) 1.0,1.8$ ). BW was decreased significantly among women with lowest decision making autonomy after adjusting for all confounders. Conclusion. Women's decision-making autonomy has an independent effect on BW and LBW outcome. In addition, there is a need for further exploration to identify sociocultural attributes and gender related determinants of women decision-making autonomy in this study setting.
\end{abstract}

\section{Background}

WHO has defined low birth weight (LBW) as birth weight (BW) less than $2500 \mathrm{~g}$ at birth which is a global public health concern [1]. About one half of the world's low birth weight (LBW) babies are born in South Asia and Bangladesh has the highest incidence $(31-47 \%)[1,2]$. BW is an important predictor of infant growth and survival and is strongly associated with early mortality and morbidity with adverse long-term outcomes $[3,4]$.

Low weight at birth is either the result of preterm delivery or intrauterine growth retardation (IUGR) [5]. BW is affected by various factors including maternal age, parity, BMI, quality of antenatal care, anaemia, and pregnancy induced hypertension (PIH) [6-10]. However, in developing countries like Bangladesh maternal undernutrition is a major determinant of LBW [11-15].
It has been reported that in many South Asian countries including Bangladesh women's socioeconomic status is low and gender inequality persists in many sectors starting from intrahousehold food allocation, education, work, and property rights to decision-making matters. The majority of women have limited access to and control over resources and restriction in their mobility and are often under threat of violence from male relatives [16-18].

Women's autonomy is a multidimensional concept that remains ill-defined. There is no single accepted definition that represents it well. In this study, women's decisionmaking autonomy is defined as women personal power in the household and her ability to make and execute independent decisions of her own concern or about close family members which is closely associated with maternal and child health outcomes [19-21].

In a recent study in South India, it was observed that women with higher decision-making autonomy on financial 
resources and freedom to go to the market were significantly less likely to have a stunted child, after controlling for socioeconomic status and mother's education [20]. There have been a number of other studies that examine different dimension of women's autonomy and its relationship with reproductive health and health outcomes such as maternal and child health care utilisation $[22,23]$, reproductive preferences [24], and contraceptive use $[25,26]$. A study done by Bloom et al., 2001, in North India shows that women's autonomy is the major determinant of maternal health care utilisation. Women with greater freedom of movement are more likely to receive antenatal care and to use delivery care, and the authors suggested that women's autonomy is equally important to educational and economic characteristics.

In order to address the LBW issue successfully, in a country like Bangladesh, where maternal undernutrition and LBW are prevalent, it could be important to explore the role of women's decision-making autonomy in relation with birth weight. The aim of this study is to assess the effect of women's decision-making autonomy on infant's birth weight in rural Bangladesh. We hypothesized that women with lowest decision-making autonomy are more likely to have LBW babies than women with highest decision-making autonomy.

\section{Methods}

2.1. Study Setting. The study was conducted in Matlab, a poor rural subdistrict within Chandpur district in Bangladesh, located about $55 \mathrm{~km}$ southeast of Dhaka, the capital. The main economic activities of the area are farming and fishing. Rice and fish are the common staple food.

The women status is low in general, and traditional social and cultural norms curtail the women's autonomy. It has been reported that, although in recent years the freedom and status of women have improved in this setting due to various women empowerment programs such as microcredit organization and other NGOs, it is still far from advantageous. It is unusual for the majority of women to leave their home without a male companion which limits their opportunities for employment outside their homestead [27]. A girl usually marries in her teens and moves into her husband's home and loses the support network from her native family [17].

Since 1966 International Centre for Diarrhoeal Disease Research, Bangladesh (ICDDR, B), has run a Health and Demographic Surveillance System (HDSS) in Matlab covering a population of 220,000 that has collected vital demographic information (births, deaths, fertility, migrations, marriages and divorces, and household divisions). These data are updated by monthly home visits by trained Community Health Research Workers (CHRW) [27].

2.2. Study Subjects. The study included data from the Maternal and Infant Nutritional Intervention in Matlab (MINIMat study), which is a combined intervention trial to promote maternal and infant health by providing prenatal food and micronutrients supplementation during pregnancy. Within HDSS system, pregnant women were identified by trained
CHRWs on their monthly household visits. All pregnant women aged 14-45 years in the area were eligible for enrolment in the study. The inclusion criteria were gestation less than 14 weeks with ability to give consent. Urine pregnancy tests were performed in the field whenever a woman reported that her last menstrual period (LMP) was overdue by two weeks or more or that she understood that she was pregnant and later confirmed by ultrasonography at her first clinic visit. After confirmation of pregnancy women were closely followed throughout their pregnancy until delivery. Out of 4436 enrolled, 2175 participants who had complete information on birth weight and decision-making autonomy were included in the analysis.

2.3. Data Collection and Quality Control of Data. ICDDR, B was responsible for all data collection. Data were collected by trained interviewers and paramedics from November 2001 to October 2003. Structured questionnaires with precoded questions were used for data collection. All questionnaires were pretested and revised accordingly by the responsible investigators before introducing them in the study.

A female field assistant measured weight and height of all enrolled women and collected sociodemographic information including women's age, parity, educational status, income, household assets, husband's education, and decision autonomy. We used the wealth index created by MINIMat team from the information on household assets to measure socioeconomic status (SES) of women [28]. All collected data were routinely reviewed once every two weeks by the responsible investigators.

2.4. Ethical Considerations. Written consent was obtained from each woman before enrolment in the study. The women were informed that they had the right to withdraw from the study at any point without any consequences for access to or use of routine ICDDR, B and government health care services. Confidentiality of information was strictly maintained. Ethical approval for this study was obtained from the Ethical Review Committee of ICDDR, B.

\subsection{Anthropometric Measurements}

2.5.1. Birth Weight. Research assistants were trained to carry out the anthropometric measurements as per WHO guidelines. Weighing equipment was standardized daily with standard weights. Women were provided with a "birth notification" card that should be sent to the study office immediately after delivery. It also contained an incentive to do so by promising a small amount of money to reimburse travel cost. The infant birth weight was measured within 72 hours of delivery by using beam scales (Seca $\mathrm{GmbH}$ ), with a precision of $10 \mathrm{~g}$. We used WHO cutoff for low birth weight (LBW) which refers infants born weighing less than $2.5 \mathrm{~kg}$, regardless of gestational age and the cause of LBW.

2.5.2. Maternal Body Mass Index (BMI). The weight of the pregnant women was measured with a precision of $0.1 \mathrm{~kg}$ with electronic scales (UNISCALE) that were accurate to 
$100 \mathrm{~g}$. Height was measured to a precision of $0.1 \mathrm{~cm}$ by using a stadiometer. BMI was calculated as wt $(\mathrm{kg}) / \mathrm{ht}$. $(\mathrm{m})^{2}$. We followed the WHO definition of BMI (i.e., $<18.5$ for mild undernutrition) as the cutoff for low BMI and high BMI was $>24.5$.

2.5.3. Decision-Making Autonomy. Decision-making autonomy was estimated from 6 questions on decision making, for example, decision regarding own health care, making small and large household purchases. These questions were originally developed and validated from Bangladesh Demographic and Health Survey BDHS [29]. In order to obtain information on the above measures of women's decisionmaking autonomy, each woman enrolled in the study was asked the following questions at the time of her first antenatal visits: "To what extent are you able to influence decisions related to the following":

(a) When you are sick, your own health care?

(b) Making household purchases for household needs?

(c) Making large household purchases?

(d) Visits to natal relatives?

(e) Consumption of food that you like to eat?

(f) Utilisation of contraceptive methods?

To develop a score for analysis, the responses were coded as follows: (a) 3 points for decisions made by the women; (b) 2 points for women who have some influence on decisionmaking; and (c) 1 point for those who do not have any influence or a very little influence.

To facilitate analysis, a composite score ranges from 6 to 18 with a mean score 12.9 was created to measure decision making autonomy, which was further divided into tertile categories, resulting in the final score with lowest autonomy $(\leq 12)$, medium (13-14), and highest autonomy $(\geq 15)$.

2.6. Statistical Analysis. Differences in enrolment characteristics between the women with and without complete data on birth weight (BW) and decision-making autonomy were examined by using independent $t$-test and chi-square tests based on the type of variables (continuous/categorical). Bivariate association of BW with each covariate was assessed using the analysis of variance (ANOVA), independent $t$-test and chi-square tests. Covariates considered in the analysis comprised maternal age, parity, BMI, education of woman and her husband, household income, asset score, and living with mother-in-law. Confounding factors were included in the final analysis for adjustment if its influence on the effect estimate was found to be more than $10 \%$. Finally, ANCOVA and binary logistic regression were conducted with $\mathrm{BW}$ as a continuous and categorical dependent variable for both crude (model with decision-making autonomy only) and adjusted models (full model adjusted with confounding factors). All the results are reported as Mean \pm SD unless stated otherwise. A $P$ value less than 0.05 was considered as the level of statistical significance. All statistical analyses were carried out using IBM SPSS Statistics 19 for Window (SPSS Inc., Chicago, IL).

\section{Results}

Out of 4436 women in the study group, $2175(\approx 49 \%)$ with complete information on BW and decision-making autonomy were included in the final analysis. In the first step about $26 \%$ of the participants were excluded for missing information on BW while $24 \%$ were excluded later for missing information on decision-making autonomy (Figure 1). Women with complete data on BW and decision-making autonomy were slightly older and had more children, lower education, and less income. There were no significant differences in maternal height, BMI, husband education, and residing with mother-in-law between those with or without complete data. Overall women in complete group had higher mean BW and lower percentage of LBW infants than in incomplete group (Table 1).

3.1. Decision-Making Autonomy. Women in this study group appeared to hold very little decision-making power in large household purchases whereas majority (74\%) of women had their final say over food like to eat. About half of the women had some influence on decision making regarding their own health care but very few of women had final say on it. Similarly, very few women had final say on using contraception, visits to natal relatives, and making small household purchases for daily household needs (Table 2).

3.2. Effect of Decision-Making Autonomy on BW. The mean BW of children born to women with highest decisionmaking autonomy was significantly higher $(2.75 \pm 0.4 \mathrm{~kg})$ than in women with lowest decision-making autonomy $(2.67 \pm$ $0.3 \mathrm{~kg})$. In multivariate analysis, BW was significantly lower $(\approx 69 \mathrm{~g})$ in women with lowest decision-making autonomy as compared to women with highest decision-making autonomy after controlling for confounding factors like maternal age, BMI, asset scores, women and her husband's education. Maternal age, BMI, a woman education and asset scores were also found to have significant effect on birth weight (Table 3).

The proportion of LBW infants was significantly lower (24\%) in women with highest decision-making autonomy than in women with lowest decision-making autonomy (32\%). Women with lowest decision-making autonomy had $40 \%$ increased risk of having LBW babies as compared to women with highest decision-making autonomy (odds ratio $(\mathrm{OR})=1.4 ; 95 \%$ confidence Interval (CI) 1.0, 1.8). Among other covariates, maternal age and asset scores remained significantly associated with LBW in the final model (Table 4) (results were shown already).

\section{Discussion}

The findings of this study support the hypothesis that low maternal decision-making autonomy is associated with increased LBW outcome in rural Bangladesh. Women with lowest decision-making autonomy had lighter babies as compared to women with highest decision-making autonomy.

There are many direct and indirect complex pathways underlie in the relationship between women decision-making 
TABLE 1: Baseline characteristics of the participants with complete and incomplete information.

\begin{tabular}{|c|c|c|c|}
\hline Characteristic & Complete data $N=2175$ & Incomplete data $N=2261$ & $P$ value $^{\dagger}$ \\
\hline \multicolumn{4}{|l|}{ Age (years) } \\
\hline Mean age (SD) & $26 \pm 5.89$ & $25.60 \pm 6.05$ & \multirow[t]{2}{*}{0.028} \\
\hline$\leq 18$ & $195(9.0)$ & $253(11.3)$ & \\
\hline $19-34$ & $1776(81.7)$ & $1784(79.4)$ & \multirow[t]{2}{*}{0.040} \\
\hline$\geq 35$ & $204(9.4)$ & $210(9.3)$ & \\
\hline \multicolumn{4}{|l|}{ Parity } \\
\hline 0 & $681(31.3)$ & $819(36.4)$ & \multirow{4}{*}{0.005} \\
\hline $1-2$ & $1087(50)$ & $1034(46.0)$ & \\
\hline $3-4$ & $335(15.4)$ & $324(14.4)$ & \\
\hline$\geq 5$ & $70(3.2)$ & $71(3.2)$ & \\
\hline \multicolumn{4}{|l|}{ Height $(\mathrm{cm})$} \\
\hline Mean ht. (SD) & $149.74 \pm 5.34$ & $149.79 \pm 5.31$ & 0.732 \\
\hline \multicolumn{4}{|l|}{ Weight (kg) } \\
\hline Mean wt. (SD) & $45.28 \pm 6.74$ & $45.47 \pm 7.08$ & 0.361 \\
\hline \multicolumn{4}{|l|}{ BMI $\left(\mathrm{kg} / \mathrm{m}^{2}\right)$} \\
\hline$\leq 18.49$ & $596(27.4)$ & $620(27.5)$ & \multirow{3}{*}{0.757} \\
\hline $18.50-24.99$ & $1454(66.9)$ & $1493(66.3)$ & \\
\hline$\geq 25$ & $123(5.7)$ & $139(6.2)$ & \\
\hline Mean (SD) & $20.17 \pm 2.64$ & $20.23 \pm 2.73$ & 0.464 \\
\hline \multicolumn{4}{|l|}{ Women education (y) } \\
\hline 0 & $674(31.0)$ & $755(33.4)$ & \multirow{3}{*}{0.025} \\
\hline $1-5$ & $500(23.0)$ & $448(19.8)$ & \\
\hline$>5$ & $1001(46.0)$ & $1058(46.8)$ & \\
\hline Mean (SD) & $5 \pm 4.04$ & $5.04 \pm 4.23$ & 0.800 \\
\hline \multicolumn{4}{|l|}{ Lives with mother-in law } \\
\hline No & $956(44.1)$ & $937(41.6)$ & \multirow{2}{*}{0.085} \\
\hline Yes & $1210(55.9)$ & $1317(58.4)$ & \\
\hline \multicolumn{4}{|l|}{ Husband education (y) } \\
\hline 0 & $670(31.0)$ & $676(30.1)$ & \multirow{3}{*}{0.655} \\
\hline $1-5$ & $510(23.6)$ & $519(23.1)$ & \\
\hline$>5$ & $982(45.4)$ & $1051(46.8)$ & \\
\hline Mean (SD) & $5.37 \pm 4.54$ & $5.54 \pm 4.65$ & 0.239 \\
\hline \multicolumn{4}{|l|}{ A stable household of income } \\
\hline No & $1247(57.3)$ & $1183(52.3)$ & \multirow{2}{*}{0.001} \\
\hline Yes & $928(42.7)$ & $1078(47.7)$ & \\
\hline \multicolumn{4}{|c|}{$\begin{array}{l}\text { Household income and expenditure } \\
\text { situation in last year }\end{array}$} \\
\hline Surplus & $564(26.0)$ & $635(28.2)$ & \multirow{4}{*}{0.205} \\
\hline Expenditure equaled income & $1171(54.0)$ & $1200(53.2)$ & \\
\hline Occasional deficit & $376(17.3)$ & $351(15.6)$ & \\
\hline Constant deficit & $58(2.7)$ & $68(3.0)$ & \\
\hline \multicolumn{4}{|l|}{ Calculated asset scores } \\
\hline Poor & $414(19.0)$ & $474(21.0)$ & \multirow{5}{*}{0.404} \\
\hline Below middle & $454(20.9)$ & $437(19.3)$ & \\
\hline Middle & $425(19.5)$ & $458(20.3)$ & \\
\hline Upper middle & $442(20.3)$ & $445(19.7)$ & \\
\hline Rich & $440(20.2)$ & $447(19.8)$ & \\
\hline
\end{tabular}


TABLE 1: Continued.

\begin{tabular}{lccc}
\hline Characteristic & Complete data $N=2175$ & Incomplete data $N=2261 P$ value $^{\dagger}$ \\
\hline Birth weight $(\mathrm{g})$ & & & \\
$<2500$ & $646(29.7)$ & $351(32.1)$ & \\
$\geq 2500$ & $1529(70.3)$ & $741(67.9)$ & 0.153 \\
Mean (SD) & $2704.72 \pm 407.90$ & $2672.33 \pm 415.01$ & $\mathbf{0 . 0 3 3}$ \\
\hline
\end{tabular}

${ }^{\dagger}$ Differences assessed with independent $t$-test for continuous variables and with Pearson's chi-square tests for categorical variables. Bold font refers to statistical significance.

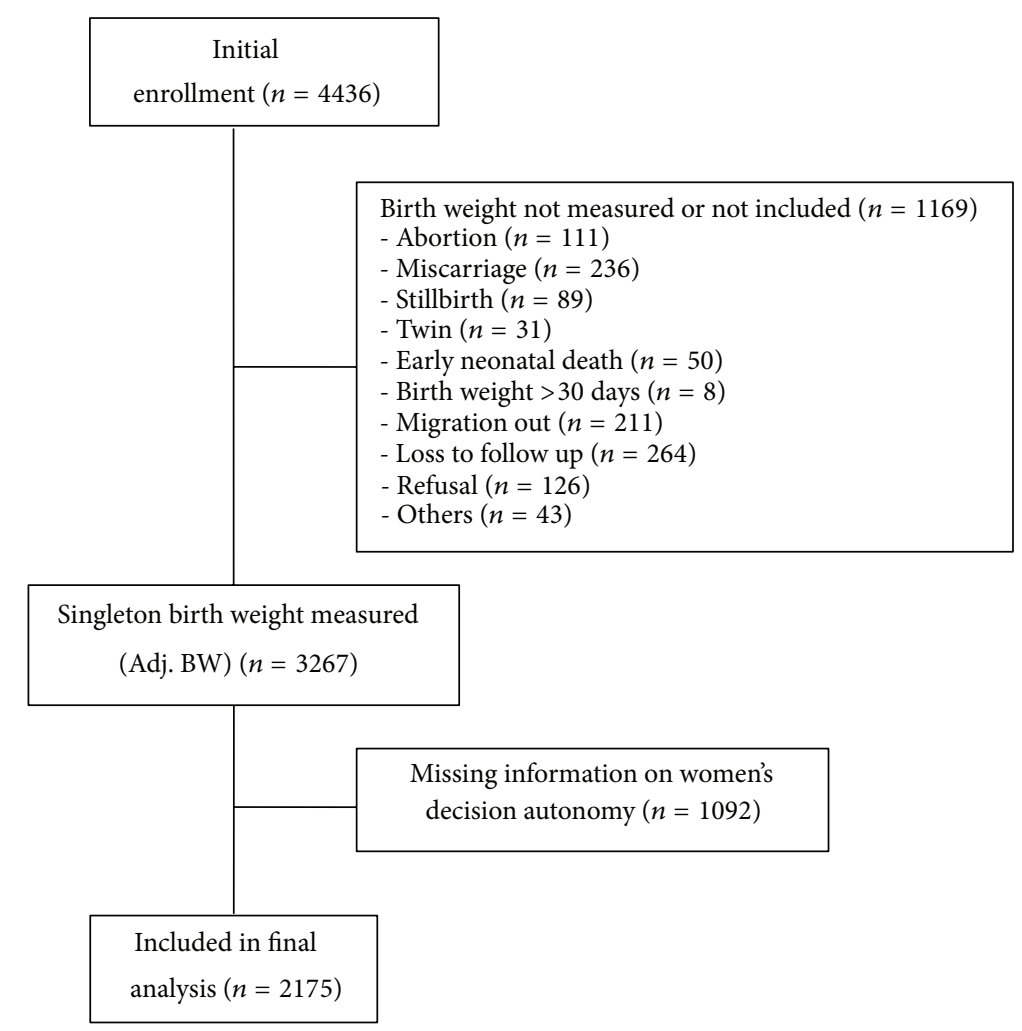

Figure 1: Study participation.

autonomy and infant's BW. Women decision-making autonomy can affect infant BW by affecting women's health and nutritional status and foetal growth.

Women's low social status in Bangladesh followed by lack of decision-making autonomy on cooking or food choices can influence her health and nutritional status directly through dietary discriminatory practices such as unfair food sharing, inadequate and improper diet intake during pregnancy giving rise to maternal undernutrition and LBW outcome $[12,30]$.

Maternal under nutrition is a major determinant of LBW in a developing country like Bangladesh. The proportion of babies born with LBW reflects poor maternal health and nutritional status not only during pregnancy but over the whole life cycle of their childhood and young lives [3]. Poor maternal nutritional status at conception, low gestational weight gain due to inadequate dietary intake, and short maternal stature due to mother's own childhood malnutrition and micronutrients deficiencies are responsible for maternal under nutrition $[12,13]$. Based on this concept, we can hypothesize that women with low decision-making autonomy on cooking or food choices are more likely to have LBW infants due to under nutrition and impaired foetal growth in-utero.

Woman's autonomy regarding decision making on her own health care is also closely linked with maternal and child health outcome. A study based in three South Asian countries revealed that decisions of women's health care were made without their participation for the majority of women in Nepal, approximately half in Bangladesh (54.3\%) and (48.5\%) in Indian households [21]. This finding is consistent with our findings which reflects that only $29 \%$ of women had a final say on decision making of their own health care and $67 \%$ of them had only some influence. Women with lack of decisionmaking autonomy on their health care are less likely to obtain regular health checkups including antenatal care, which covers iron and folic acid supplementation, Tetanus toxoid immunization, safe delivery practices, and important health information regarding pregnancy and childbirth. Beside this, low level of decision-making autonomy on health care can lead to low uptake of prenatal food and micronutrient 
TABLE 2: Summary statistics of decision autonomy scores $(n=2175)$.

\begin{tabular}{|c|c|c|c|}
\hline Characteristics & $\begin{array}{l}\text { (1) A little or no influence } \\
\qquad N(\%)\end{array}$ & $\begin{array}{l}\text { (2) Some influence } \\
N(\%)\end{array}$ & $\begin{array}{l}\text { (3) A lot or sole decision making } \\
\qquad N(\%)\end{array}$ \\
\hline $\begin{array}{l}\text { (1) Decision regarding own } \\
\text { health care, when fall sick }\end{array}$ & $78(3.6)$ & $1465(67.4)$ & $632(29.1)$ \\
\hline $\begin{array}{l}\text { (2) Making small household } \\
\text { purchases for household needs }\end{array}$ & $393(18.1)$ & $1039(47.8)$ & $743(34.2)$ \\
\hline $\begin{array}{l}\text { (3) Making large household } \\
\text { purchases }\end{array}$ & $943(43.4)$ & $1149(52.8)$ & $83(3.8)$ \\
\hline (4) Visit to natal relatives & $292(13.4)$ & $1238(56.9)$ & $645(29.7)$ \\
\hline $\begin{array}{l}\text { (5) Consumption of foods like to } \\
\text { eat }\end{array}$ & $80(3.7)$ & $486(22.3)$ & $1609(74.0)$ \\
\hline (6) Use of contraception & $173(8.0)$ & $1659(76.3)$ & $343(15.8)$ \\
\hline
\end{tabular}

TABLE 3: Association of BW with decision-making autonomy using analysis of covariance (ANCOVA) with crude and adjusted models; $B$ (coefficient) and 95\% confidence intervals (CI).

\begin{tabular}{lcccc}
\hline & \multicolumn{2}{c}{ Model with autonomy only } & \multicolumn{2}{c}{ Full model $^{1}$} \\
& $B$ & $(95 \% \mathrm{CI})$ & $B$ & $(95 \% \mathrm{CI})$ \\
\hline $\begin{array}{l}\text { Decision-making autonomy (Tertile) } \\
\quad \text { Highest (Reference) }\end{array}$ & - & - & - & - \\
$\quad$ Average & -46.8 & $(-92.8,-0.96)^{*}$ & -30.0 & $(-75.2,15.1)$ \\
$\quad$ Lowest & -87.9 & $(-132.6,-43.2)^{* *}$ & -68.8 & $(-114.4,-23.2)^{* *}$ \\
\hline
\end{tabular}

${ }^{1}$ Adjusted for maternal age, BMI, asset scores, maternal education, and husband's education.

${ }^{*} P$ value at $<0.05,{ }^{* *} P$ value at $<0.01$.

TABLE 4: Association of LBW with decision-making autonomy using binary logistic regression with crude and adjusted models; odds ratio (OR) and $95 \%$ confidence intervals (CI).

\begin{tabular}{|c|c|c|c|c|}
\hline & \multicolumn{2}{|c|}{ Model with autonomy only } & \multicolumn{2}{|c|}{ Full model } \\
\hline & Crude OR & (CI) & Adjusted $\mathrm{OR}^{1}$ & $(\mathrm{CI})$ \\
\hline \multicolumn{5}{|c|}{ Decision-making autonomy (Tertile) } \\
\hline Highest & 1 & Reference & 1 & Reference \\
\hline Average & 1.30 & $(1.0,1.6)^{*}$ & 1.24 & $(0.9,1.6)$ \\
\hline Lowest & 1.46 & $(1.1,1.8)^{* *}$ & 1.40 & $(1.0,1.8)^{*}$ \\
\hline
\end{tabular}

${ }^{1}$ Adjusted for maternal age, asset scores, maternal education and husband education.

${ }^{*} P$ value at $<0.05,{ }^{* *} P$ value at $<0.01$.

supplementation in our study setting. Lack of this could contribute to poor prenatal care, poor maternal health and nutritional status, and impaired foetal growth leading to LBW.

A study in South India suggested that women's permission to go to the market or to visit natal relatives could potentially provide a forum for exchanging health related information and could receive prenatal care earlier in their pregnancy and treatment for disease associated with IUGR such as hypertension and heart disease that may lead to better birth outcome [20]. On the other hand, other studies have explored the relationship between women autonomy and maternal health care utilisation using different aspects of autonomy such as financial autonomy, decision-making autonomy, and mobility autonomy. The results revealed that women with greater freedom of movement obtained better antenatal care and were more likely to use safe delivery care which can affect birth weight $[19,22]$.

Apart from this study, many other studies have examined the role of women's autonomy in fertility preferences and use of contraception [24, 26]. Women's final say in decision regarding day to day household purchases and spousal communication is significantly associated with fertility preferences and use of contraception which may facilitate proper birth spacing and prevent early pregnancy and childbirth which can also help to reduce the LBW prevalence [25].

Women in South Asian countries including Bangladesh are often under threat of violence due to their subordinate position [16]. They may have less possibility for decision making in the household in different sectors such as decision making for herself or her family members, purchasing food, control over resources, and so forth, which might affect her health and nutritional status as well as foetal growth and development, giving rise to LBW babies [31].

A study in Bangladesh reported that $50 \%$ of women experiencing some form of family violence had LBW babies followed by early childhood growth impairment. We hypothesize that women with low decision-making autonomy are more likely to face any kind of violence which might affect infant's birth weight through several mechanisms. Direct 
physical trauma to pregnant women's abdomen may lead to preterm delivery along with other serious maternal and foetal complications. It has been reported that stress and depression related with all forms of violence can increase the risk of impaired foetal growth and LBW [31]. Antenatal depression was also found to be associated with foetal growth retardation [32].

Many researchers have suggested that stress and depression cause disturbances in hypothalamic-pituitary-adrenal axis giving rise to increased level of stress hormones which affects intrauterine environment resulting in IUGR. Similarly, activation of sympathetic-adrenal-medullary system resulting in vasoconstriction and hypoxia with decreased uteroplacental perfusion contributes to growth restriction and LBW. However, further exploration is required to find out the exact mechanism [31, 33]. Along with stress and depression, violence is often accompanied by social isolation and lack of social support which may affect infant's BW [33].

A major strength of the study is randomized enrolment of pregnant women over the survey period which makes the results relatively representative of the study population, and hence the findings can be appropriately generalized to women in similar rural areas of Bangladesh. The socioeconomic characteristics of this study rural area in Matlab were similar to those of national level according to the census of Matlab HDSS study area in 2005. These findings in Matlab can be applied to or are important to other populations in the world.

However, there are some limitations and some sources of bias in this study.

Understanding the role of women's decision-making autonomy in relation to BW is complex because of its multidimensionality and difficulty in formulating an appropriate autonomy measures. In this study, we have examined only one aspect of women's autonomy, that is, decision-making autonomy. Different dimensions of autonomy might have different influence on infants BW. Along with decisionmaking autonomy we could have analysed other areas of autonomy like control over finances, freedom of movement, and woman's attitude towards domestic violence (wife beating) which could have important impact on BW in this context.

Women in our study group were significantly older and had more children which is likely to overestimate the effect. We have adjusted BMI as a confounding factor in the final multivariate model with $\mathrm{BW}$ as a continuous variable which might cause overadjustment and underestimate the effect.

\section{Conclusion}

This study revealed that women's decision-making autonomy has an independent effect on infant BW and LBW outcome after controlling for all confounders like maternal age, SES, and education. The result of our study suggests that improving women's decision-making autonomy will have a positive effect on reduction of LBW. In addition, there is a need for further exploration to identify sociocultural attributes and gender related determinants of women's decision-making autonomy in this study setting.

\section{Conflict of Interests}

The authors declare that they have no conflict of interests.

\section{Acknowledgment}

The authors would like to express deepest gratitude to scientist Dr. Eva-Charlotte Ekström at Department of Women and Child Health, IMCH, Uppsala University, Sweden, for her continuous support and invaluable guidance from the beginning of this work.

\section{References}

[1] UNICEF: Low Birthweight: Country, Regional and Global Estimates, New York, NY, USA, 2004, http://www.unicef.org/ publications/index_24840.html.

[2] G. M. Monawar Hosain, N. Chatterjee, A. Begum, and S. C. Saha, "Factors associated with low birthweight in rural Bangladesh," Journal of Tropical Pediatrics, vol. 52, no. 2, pp. 87-91, 2006.

[3] J. Pojda and L. Kelley, "Low birthweight," ACC/SCN Nutrition Policy, ICDDR B, Dhaka, Bangladesh, 2000.

[4] A. J. Wilcox, "On the importance-and the unimportance-of birthweight," International Journal of Epidemiology, vol. 30, no. 6, pp. 1233-1241, 2001.

[5] WHO, Meeting of Advisory Group on Maternal Nutrition and Low Birthweight, Geneva, Switzerland, WHO, 2002.

[6] E. M. Elshibly and G. Schmalisch, "The effect of maternal anthropometric characteristics and social factors on gestational age and birth weight in Sudanese newborn infants," BMC Public Health, vol. 8, article 244, 2008.

[7] E. Karim and C. G. N. Mascie-Taylor, "The association between birthweight, sociodemographic variables and maternal anthropometry in an urban sample from Dhaka, Bangladesh," Annals of Human Biology, vol. 24, no. 5, pp. 387-401, 1997.

[8] M. S. Kramer, "Determinants of low birth weight: methodological assessment and meta-analysis," Bulletin of the World Health Organization, vol. 65, no. 5, pp. 663-737, 1987.

[9] S. Nahar, C. G. N. Mascie-Taylor, and H. A. Begum, "Maternal anthropometry as a predictor of birth weight," Public Health Nutrition, vol. 10, no. 9, pp. 965-970, 2007.

[10] J. Valero de Bernabé, T. Soriano, R. Albaladejo et al., "Risk factors for low birth weight: a review," European Journal of Obstetrics Gynecology and Reproductive Biology, vol. 116, no. 1, pp. 3-15, 2004.

[11] S. Som, M. Pal, D. K. Adak, A. K. Gharami, S. Bharati, and P. Bharati, "Effect of socio-economic and biological variables on birth weight in madhya pradesh, india,", Malaysian Journal of Nutrition, vol. 10, pp. 159-171, 2004.

[12] K. Shannon, Z. Mahmud, A. Asfia, and M. Ali, "The social and environmental factors underlying maternal malnutrition in rural Bangladesh: implications for reproductive health and nutrition programs," Health Care for Women International, vol. 29, no. 8-9, pp. 826-840, 2008.

[13] A. S. G. Faruque, A. M. S. Ahmed, T. Ahmed et al., "Nutrition: basis for healthy children and mothers in Bangladesh," Journal of Health, Population and Nutrition, vol. 26, no. 3, pp. 325-339, 2008. 
[14] U. Ramakrishnan, "Nutrition and low birth weight: from research to practice," American Journal of Clinical Nutrition, vol. 79, no. 1, pp. 17-21, 2004.

[15] R. Shaheen, A. de Francisco, S. El Arifeen, E.-C. Ekström, and L. Å. Persson, "Effect of prenatal food supplementation on birth weight: an observational study from Bangladesh," American Journal of Clinical Nutrition, vol. 83, no. 6, pp. 1355-1361, 2006.

[16] F. F. Fikree and O. Pasha, "Role of gender in health disparity: the South Asian context," British Medical Journal, vol. 328, no. 7443, pp. 823-826, 2004.

[17] N. Islam and N. Sultana, "The Status of women in bangladesh: is the situation really encouraging?" Research Journal of Social Sciences, vol. 1, no. 1, pp. 56-65, 2006.

[18] S. M. Ahmed, A. M. Adams, M. Chowdhury, and A. Bhuiya, "Gender, socioeconomic development and health-seeking behaviour in Bangladesh," Social Science and Medicine, vol. 51, no. 3, pp. 361-371, 2000.

[19] G. Woldemicael, "Do women with higher autonomy seek more maternal and child health-care? Evidence from ethiopia and eritrea," MPIDR Working Paper, Department of Sociology, Faculty of Social Sciences, Stockholm University, Stockholm, 2007.

[20] M. Shroff, P. Griffiths, L. Adair, C. Suchindran, and M. Bentley, "Maternal autonomy is inversely related to child stunting in Andhra Pradesh, India," Maternal and Child Nutrition, vol. 5, no. 1, pp. 64-74, 2009.

[21] U. Senarath and N. S. Gunawardena, "Women's autonomy in decision making for health care in South Asia," Asia-Pacific Journal of Public Health, vol. 21, no. 2, pp. 137-143, 2009.

[22] S. S. Bloom, D. Wypij, and M. Das Gupta, "Dimensions of women's autonomy and the influence on maternal health care utilization in a North Indian city," Demography, vol. 38, no. 1 , pp. 67-78, 2001.

[23] M. Furuta and S. Salway, "Women's position within the household as a determinant of maternal health care use in Nepal," International Family Planning Perspectives, vol. 32, no. 1, pp. 1727, 2006.

[24] G. Woldemicael, "Womens autonomy and reproductive preferences in Eritrea," Journal of Biosocial Science, vol. 41, no. 2, pp. 161-181, 2009.

[25] S. Saleem and M. Bobak, "Women's autonomy, education and contraception use in Pakistan: a national study," Reproductive Health, vol. 2, no. 1, article 8, 2005.

[26] A. Al Riyami, M. Afifi, and R. M. Mabry, "Women's autonomy, education and employment in Oman and their influence on contraceptive use," Reproductive Health Matters, vol. 12, no. 23, pp. 144-154, 2004.

[27] Health and Demographic Surveillance System-Matlab, "Socioeconomic census," Scientific Report 96, 2007.

[28] K. K. Saha, E. A. Frongillo, D. S. Alam, S. E. Arifeen, L. Å. Persson, and K. M. Rasmussen, "Appropriate infant feeding practices result in better growth of infants and young children in rural Bangladesh," American Journal of Clinical Nutrition, vol. 87, no. 6, pp. 1852-1859, 2008.

[29] BDHS, Bangladesh Demographic and Health Survey 1999-2000, BDHS Dhaka, Dhaka, Bangladesh, 1999.

[30] V. Ramalingaswami, U. Jonsson, and J. Rohde, "The asian enigma," in The Progress of Nations, Unicef, New York, NY, USA, 1996.

[31] K. Å. Monemi, The impact of violence against women on child growth, morbidity and survival [Ph.D. thesis], Department of Women's and Children's Health, Uppsala University, 2008.
[32] A. Rahman, J. Bunn, H. Lovel, and F. Creed, "Association between antenatal depression and low birthweight in a developing country," Acta Psychiatrica Scandinavica, vol. 115, no. 6, pp. 481-486, 2007.

[33] P. J. Feldman, C. Dunkel-Schetter, C. A. Sandman, and P. D. Wadhwa, "Maternal social support predicts birth weight and fetal growth in human pregnancy," Psychosomatic Medicine, vol. 62 , no. 5, pp. 715-725, 2000. 


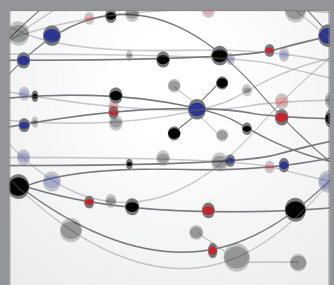

The Scientific World Journal
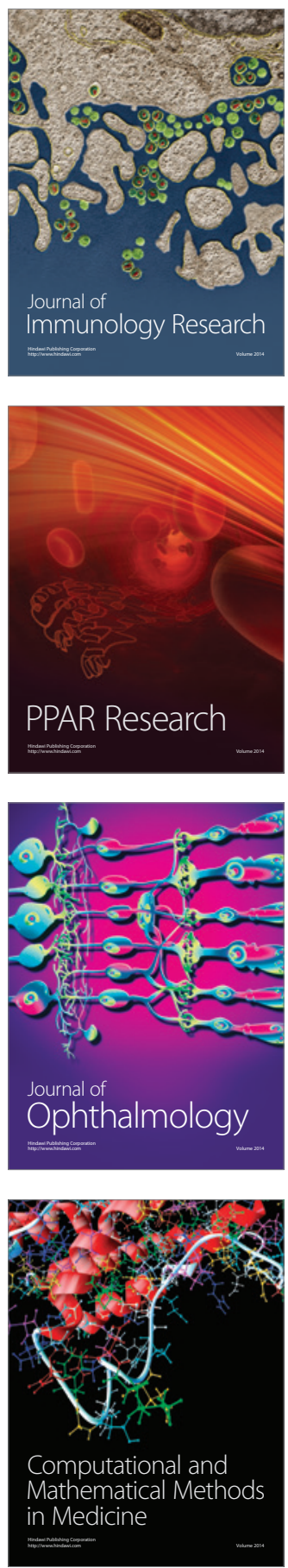

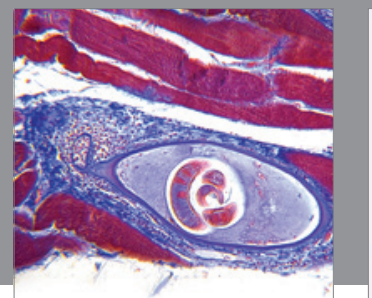

Gastroenterology

Research and Practice
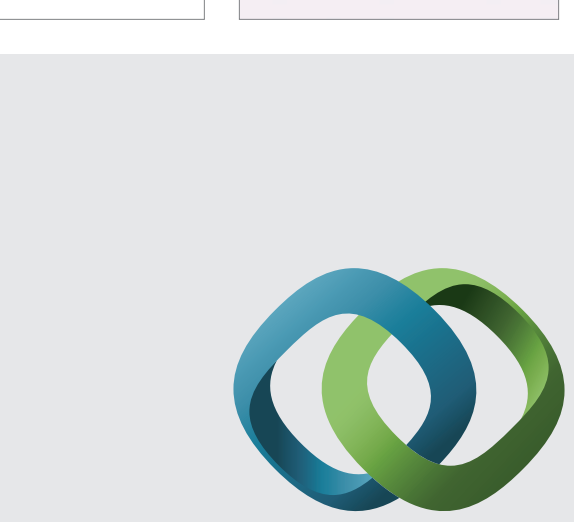

\section{Hindawi}

Submit your manuscripts at

http://www.hindawi.com
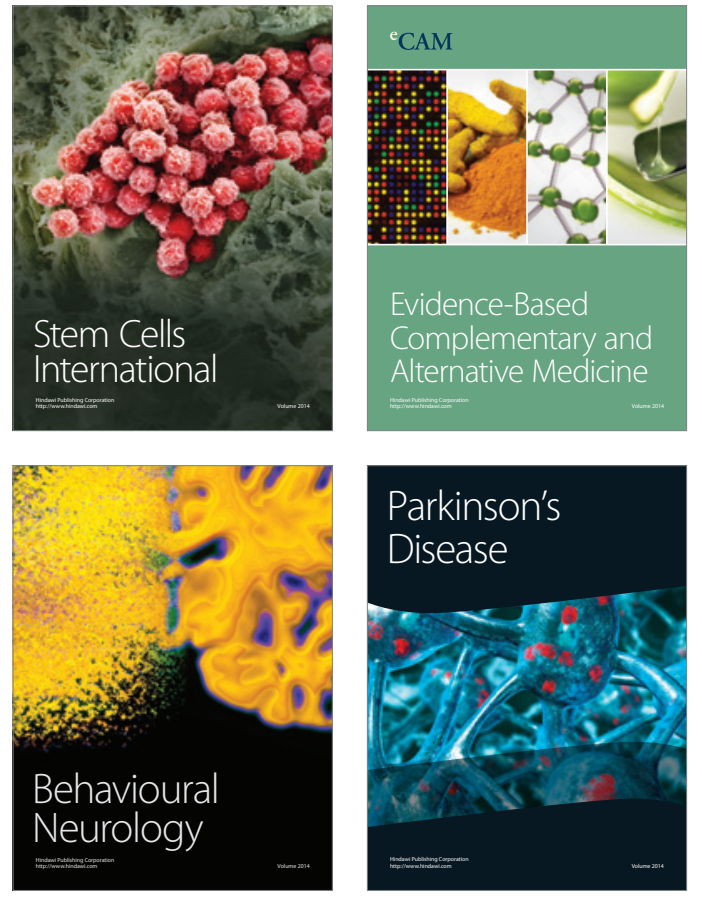
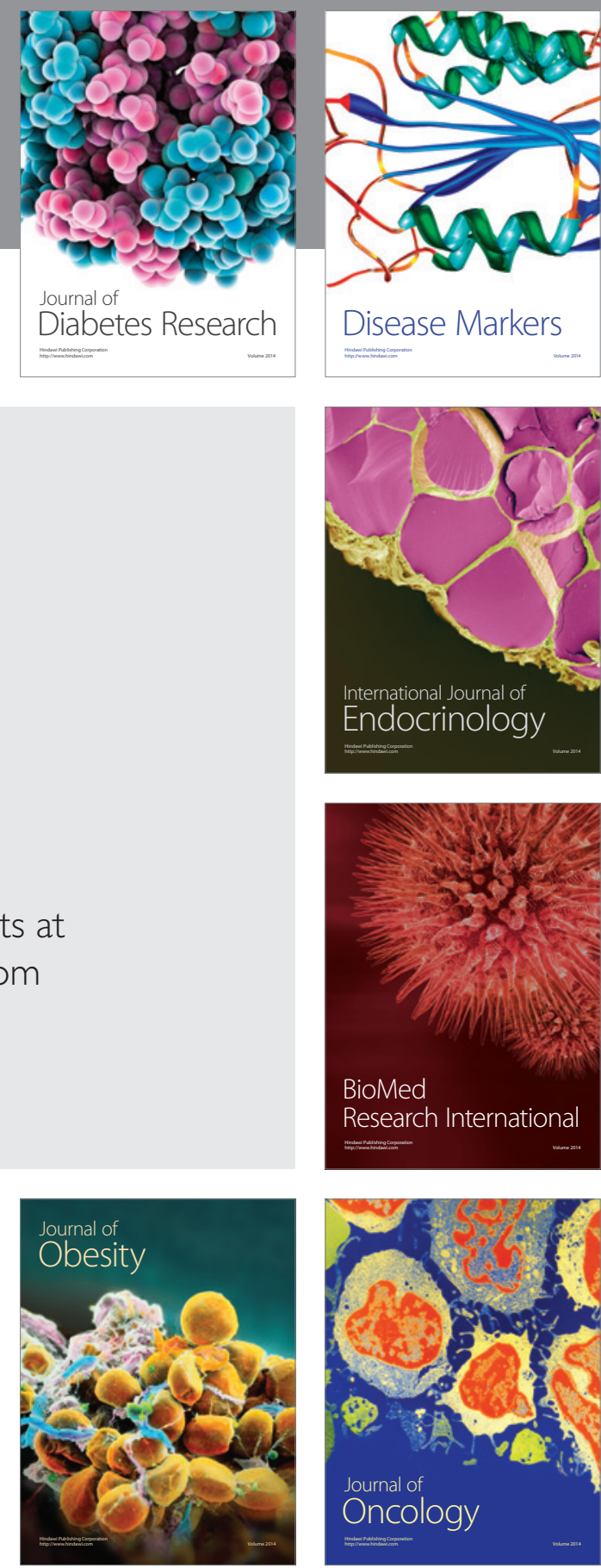

Disease Markers
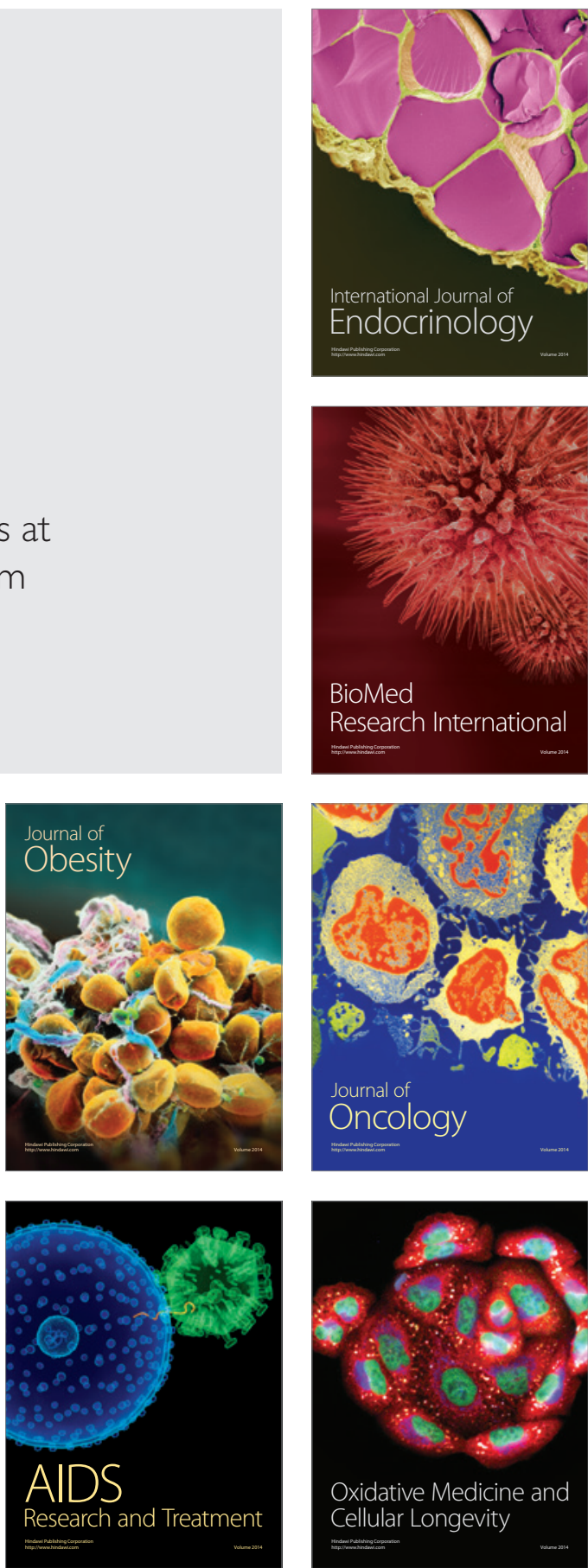